\title{
Problem Solving in the Research Laboratory -A Workshop for Graduate Students
}

\author{
Michele H. Miller \\ Michigan Technological University
}

\begin{abstract}
Graduate students often struggle to overcome the obstacles inherent in experimental work. Through practice over the course of a graduate program, many students will transition from novice to expert problem solvers even though they receive little explicit instruction on how to do this. This paper describes a workshop whose purpose is to give graduate students tools to use when encountering unexpected problems in the lab. A pilot two-hour version of the workshop was delivered to nine graduate students in January 2004. It consisted of a hands-on experiment, two brainteaser puzzles, and descriptions of several case studies. Through these activities, students learned concepts such as: playing with the experimental setup to get a feel for important factors and sources of inconsistency; evaluating whether measurement results make sense; where to start looking for culprits when results do not make sense; and breaking a complex problem down into simpler problems. Student feedback indicated they liked the workshop topic and wanted to learn more strategies for tackling problems.
\end{abstract}

\section{Introduction}

Grad students who excel in the classroom are often ill prepared for the experimental work that engineering research requires. They conduct designed experiments whose effects should have been obvious without doing the experiment. They have difficulty interpreting the meaning of real data that is messier than they expect. They lack confidence in learning new equipment and troubleshooting their experimental setup. Unfortunately (or fortunately), encountering obstacles all the time is part of the process. The unexpected makes experimental work difficult...and exciting. Problem solving in the lab involves debugging to find the reason for the problem and, when faced with limitations in equipment or time, coming up with alternative approaches to achieving goals.

The differences between novice and expert troubleshooting technicians have been characterized as shown in Table 1. With much practice in the lab many, but not all, graduate students become expert troubleshooters and problem solvers. More explicit instruction and opportunities for practice may speed up this transition.

Table 1: Characteristics of troubleshooting technicians (Perez, 1991)

\begin{tabular}{|l|l|}
\hline \multicolumn{1}{|c|}{ Novice } & \multicolumn{1}{c|}{ Expert } \\
\hline Physical, surface aspects & Functional aspects \\
\hline $\begin{array}{l}\text { Despite work on system A, system B seems } \\
\text { totally new }\end{array}$ & $\begin{array}{l}\text { Work on system A transfers to work on new } \\
\text { system B }\end{array}$ \\
\hline Has "what it is" knowledge & $\begin{array}{l}\text { Has "what it is" and "how it works" } \\
\text { knowledge }\end{array}$ \\
\hline
\end{tabular}

Proceedings of the 2005 American Society for Engineering Education Annual Conference and Exposition Copyright (C) 2005, American Society for Engineering Education 
An undergraduate engineering education does an inadequate job in preparing graduate students to solve novel problems. Undergraduates are given many opportunities to memorize procedures for solving particular types of problems (Woods, 1987). However, this experience doesn't usually prepare students for solving new types of problems. When doing research in the lab, it seems as if every problem that arises is unique. In addition, most coursework emphasizes getting the right answer. A greater emphasis on solution attempts would be better preparation for research work. For example, to explain an experimentally observed phenomenon a researcher might conduct additional experiments under different conditions using different measurement sensors. The researcher makes her best guess on which conditions and measurements to try first but usually has to try several things. Another common research problem is how to accommodate limitations in hardware. Again, the researcher may have to try several things before arriving at a best solution.

To begin to address some of the issues described above, a workshop was developed that would give graduate students some simple tools for tackling unexpected problems in the lab. The pilot workshop was delivered to nine mechanical engineering graduate students in January 2004. The two-hour workshop included a hands-on experiment, brainteaser puzzles, and discussion of case studies.

\section{Hands-on Experiment}

The hands-on experiment was adopted from the Experimental Design course of the Ford Technical Education Program. The experiment involves a ball rolling down a ramp and into a funnel where it swirls around and then drops through the hole onto the table. Figure 1 shows the experimental setup. The goal is to find the factors affecting swirl time. While the Ford course emphasizes factorial experimental designs, the workshop focused on other aspects of the process of conducting experiments, such as improving repeatability of the measurements. Students were given a 3-foot ramp (aluminum angle iron), 1 inch steel ball, plastic funnel, stopwatch, and clamps/stands (from chemistry department). Four groups of 2-3 students worked on this.

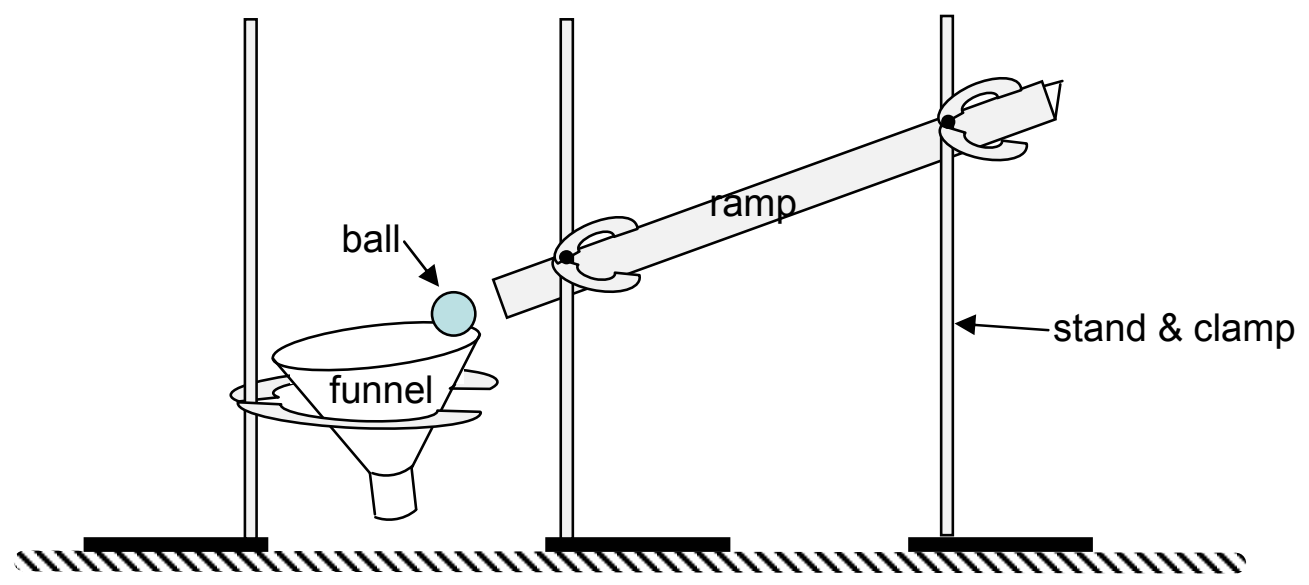

Figure 1: Illustration of setup for swirl time experiment 
The experiment was done in two parts. In the first part students were given the goal of achieving a 10 second swirl time. After 25 minutes of trial and error, one group was achieving swirl times of 10 seconds and higher. The others were achieving only a few seconds of swirl time.

In the second part students performed a full factorial experiment with 3 factors: (1) starting point on ramp; (2) operator hat; (3) ramp/funnel incidence angle. Students chose two levels for each factor. They recorded swirl times on a worksheet and computed the significance of each factor. Inclusion of operator hat (the student releasing the ball would wear a hat for half of the trials) as a factor gave a measure of error. At the completion of this part of the exercise, students had gained a lot of control over swirl time. All groups easily achieved 10 second and higher swirl times.

In addition to demonstrating the utility of the factorial design method, this exercise presented several other lessons. For example, students periodically evaluated whether their measurement results made sense. They identified conditions that led to inconsistent results, such as the ball popping out of the funnel or dropping immediately through the hole. The made improvements to their setup and procedure that improved consistency. For example, they accurately marked the ball release point, and they tightened the funnel clamp to minimize shifting. The first part of the exercise gave students time to play with the experiment to develop some intuition about what will happen. Because this experiment (like most) didn't work perfectly the first time, these preliminary tests were necessary to work out some of the bugs.

\section{Brainteaser Puzzles}

Two puzzles were presented. While they served as a fun interlude, they also demonstrated principles that could be applied to other problem solving situations. The first was the " 8 Poker Chips Problem" illustrated in Figure 2 (Hayes, 1981). A couple students eagerly jumped into this puzzle and solved it fairly quickly. On the opposite end of the spectrum were a couple students who were hesitant (perhaps uncomfortable with competitive atmosphere). Within 10 minutes, nearly every student had solved the puzzle. Most figured out the right pattern of moves by working first with 1 or 2 blue and white chips. Once they figured that out, the solution to the complex problem followed quickly. This problem presented a nice demonstration of the strategy of solving the simpler problem first.

\section{Go from:}

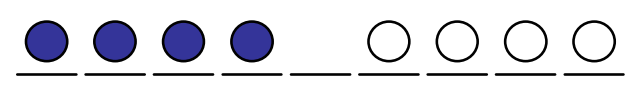

To:

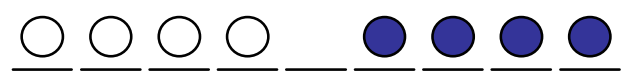

Allowable moves:

A chip can move to an adjacent space.

A chip can jump over one other chip (of either color) to an empty space.

Blue chips can only move to the right, and white chips only to the left.

Figure 2: Description of 8 Poker Chips Problem

The second brainteaser was the "Engineering Summit Problem" (also adapted from Hayes, 1981) illustrated in Figure 3. 
Make seating assignments for 16 attendees at an engineering summit given the following conditions:

- 4 Tables with 4 chairs at each.

- 4 Schools (MTU, U of M, MSU, $U$ of $W$ ) bring 4 people with different majors (ME, Biomed, EE, ChemEng).

- There are 8 women and 8 men.

- Make assignments such that each table has a person from each school, a person from each major, and 2 men and 2 women.

Figure 3: Description of Engineering Summit Problem

This is another complex problem where students need to adopt a strategy. There are 3 constraints: (1) mixing the schools so that there is one representative at each table; (2) mixing the majors so that there is one at each table; (3) mixing the genders so that there are 2 men and 2 women at each table. From this exercise, students learned to "try something." A strategy for this or other problems with multiple constraints is to first meet one of the constraints (either school, major, or gender). Subsequently, minor adjustments can be made in an attempt to meet a second constraint and then a third.

Many books offer numerous brainteaser type problems. While some have limited practical value relative to lab work, many could be adopted to illustrate strategies that also apply to solving problems in the lab. For example, in solving ill-defined problems, a useful strategy is to start with a graphical representation of what is known and unknown. Many brainteasers give practice in making assumptions and inferences to reveal more "knowns" than was initially apparent.

\section{Case Studies}

Several cases were discussed based on experiences with graduate students in my research lab. A common problem is noisy data. I discussed one particular graph of noisy force data and the steps that the student took to investigate and eliminate the sources of noise. Another case involved hardware that didn't seem to be operating properly. I described the unusual behavior that caught the student's attention and then the steps we went through to isolate the source of that behavior. A third case involving temperature measurement is described in more detail below.

A recent student project was to determine how vibration assistance affects machining temperatures. Figure 4 shows the setup for a temperature measurement experiment. A thermocouple is embedded in a steel workpiece that translates left and right under a grinding wheel. As the grinding wheel removes material from the workpiece, the temperature is recorded. Figure 4 shows the temperature measurement for two machining passes. As was done with the swirl experiment described above, the student evaluated the reasonableness of the data. Based on similar measurements taken by others, the measurement data looked strange. We then tried a number of things to figure out what was wrong. Figure 5 describes the steps in our diagnosis. The problem was resolved by drilling and tapping new holes in the workpieces. Figure 6 shows a temperature measurement result after modifying one of the workpieces. This result makes more sense. 

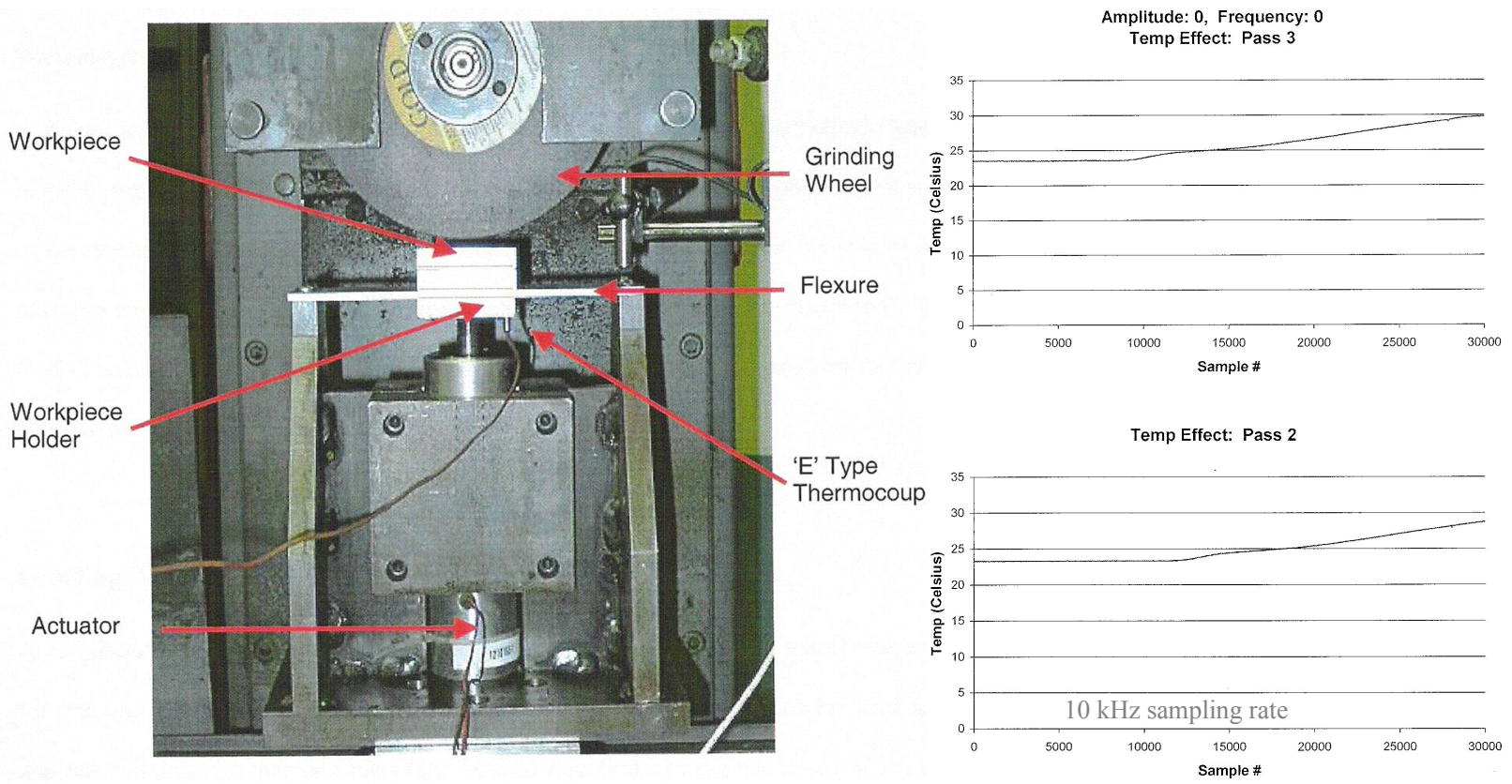

The temperature rise was smaller and slower than we expected.

Figure 4: Experimental setup and preliminary temperature measurement results

We checked our expectation for temperature rise by performing some analytical temperature predictions. These predicted a quick temperature rise (less than $1 \mathrm{sec}$ ) and 10's of degrees of rise. We checked the thermocouple by immersing it in hot water and cold water and collecting the temperature measurements. These simple trials showed us that the thermocouple was working properly and that it could respond quickly.

Then we suspected that the thermocouple wasn't making good contact with the workpiece. We measured the length of the thermocouple and how much of it sticks out of the workpiece when screwed into its mounting hole. Then we removed the thermocouple and measured the depth of the hole. It turns out that the thermocouple tip was not touching the bottom of the hole as intended. The thread didn't extend deep enough into the hole.

Figure 5: Diagnosis of the problem

Gap between thermocouple tip and workpiece

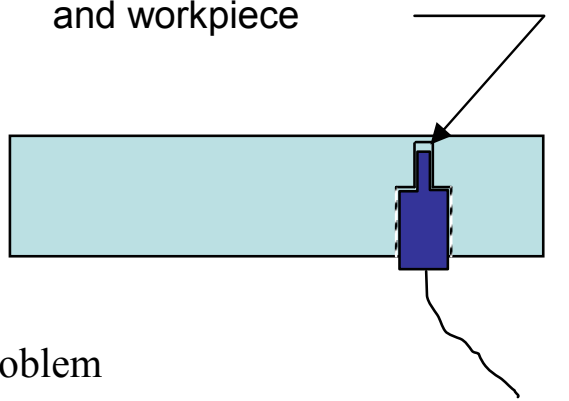

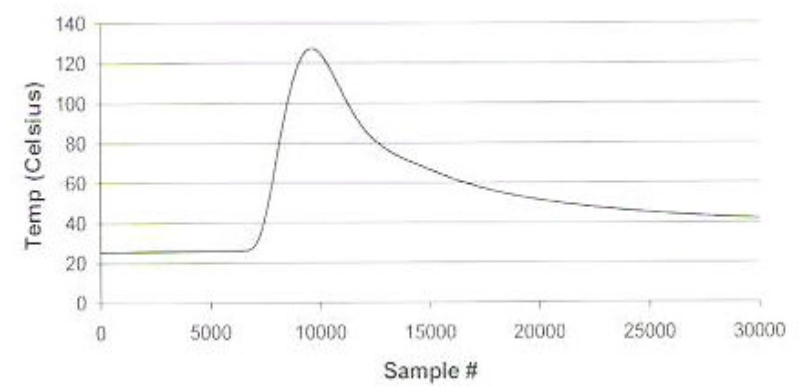

Figure 6: Measurement result after fixing the problem with the thermocouple attachment

Proceedings of the 2005 American Society for Engineering Education Annual Conference and Exposition

Copyright (C) 2005, American Society for Engineering Education 
The case studies illustrated a few of the problems that can arise when doing experiments. However, this limited number of case studies may not help students solve other types of problems that they encounter. A large library of cases is necessary. Ideally, the cases would be interactive: rather than simply presenting what was done and what the solution was, students would choose different courses of action.

\section{Conclusions and Future Work}

Student evaluations at the end of the workshop indicated they are hungry for opportunities to learn this type of material. Some students preferred the hands-on activities, but many wanted more lecturing on case studies. More work needs to be done at the undergraduate and graduate levels to teach problem solving in a way that can be applied to novel problems. In parallel to making improvements to the existing workshop, future work includes the development of computer-based simulations in which problem solving can be practiced.

\section{Acknowledgments}

This work was supported in part by NSF grant no. 9875251.

\section{References}

Ford Design Institute Technical Education Program, Experimental Design, Version 1.0, 1996. Hayes, J. R., The Complete Problem Solver, Philadelphia: Franklin Institute Press, 1981.

Perez, R. S., "A View from Troubleshooting," Toward a Unified Theory of Problem Solving, Ed. M. U. Smith, Hillsdale, NJ: Lawrence Erlbaum Associates, 1991, pp. 115-153.

Woods, J. R., "How Might I Teach Problem Solving," Developing Critical Thinking and Problem-Solving Abilities, Ed. J. E. Stice, San Francisco: Jossey-Bass, 1987, pp. 55-71.

\section{Author Biography}

MICHELE H. MILLER is an Associate Professor at Michigan Technological University where she has been a faculty member since 1994. She received her Ph.D. in Mechanical Engineering from North Carolina State University. She teaches courses on manufacturing and does research in the areas of precision engineering, machining, and microsystems. 